\title{
Documentos
}

\section{Cáncer cérvicouterino y virus del papiloma humano}

\author{
Guadalupe Zaldívar Lelo de Larrea. ${ }^{1}$, Francisco Martín Molina. ${ }^{4}$, Carlos Francisco Sosa \\ Ferreyra. ${ }^{2}$, Javier Ávila Morales. ${ }^{1}$, Miguel Lloret Rivas. ${ }^{1}$, Monserrat Román Lara. ${ }^{3}$, Ge- \\ naro Vega Malagón. ${ }^{1}$
}

${ }^{1}$ Facultad de Medicina, ${ }^{2}$ Facultad de Ciencias Naturales, ${ }^{3}$ Facultad de Química, Universidad Autónoma de Querétaro, México. ${ }^{4}$ Banco de Células Madres de Andalucía, España.

\section{RESUMEN}

El cáncer cérvicouterino $(\mathrm{CaCu})$ es la segunda causa de muerte por cáncer en mujeres de todo el mundo, a pesar de la implementación de la citología de cérvix para su prevención. Esto se debe a la baja sensibilidad y especificidad de la prueba, lo cual apoya a un cambio urgente en la forma de tamizaje para su detección. Ahora se sabe que la infección persistente por virus del papiloma humano de alto riesgo (HR-HPV) es la causa de la totalidad de los casos de $\mathrm{CaCu}$. En la actualidad se están utilizando vacunas frente a dos (Bivalente: HPV-16 y HPV-18) o cuatro (Tetravalente: HPV-6 HPV-11, HPV-16 y HPV-18) de las cepas de HRHPV que causan la mayoría de los casos de $\mathrm{CaCu}$. El propósito de este artículo es proporcionar una revisión de las características principales del virus y de los mecanismos que se echan a andar bajo la infección persistente de las células cervicales, lo cual conduce a la proliferación desordenada y a la malignización de las células infectadas. Es necesario que el virus se integre al genoma de la célula epitelial para que inicie la expresión de las oncoproteínas virales E6 y E7 lo cual conducirá al desarrollo del CaCu.

\section{PALABRAS CLAVE: Cáncer cérvicouterino, virus del papiloma humano, oncoproteína E6, oncoproteína E7, Papanicolaou}

\section{SUMMARY}

Cervical cancer (CC) is the second cause of death for cancer in women worldwide in spite of the implementation of cervix cytology screenings for its prevention. The low sensibility and specificity of the test reduce the potential benefits of these screenings and supports urgent improvements in early detection tests for CC. It is now known that persistent infection with the high-risk human papiloma virus (HR-HPV) is the causal agent of almost all cases of CC. HR-HPV vaccines effective against two (Bivalent: HPV-16 and HPV-18) or four (Tetravalent: HPV-6 HPV-11, HPV-16 and HPV-18) strains that are responsible of the majority of the $\mathrm{CC}$ cases have been licensed in several countries. The present study aims to provide a review of the principal characteristics of the HR-HPV virus and of the mechanisms that take to the persistent infection of the cervical cells leading to abnormal proliferation and malignancy. It is necessary that the virus integrates into the genome of the epithelial cell to initiates the expression of the E6 and E7 viral oncoproteins which will lead to the development of the CC.

KEY WORDS: Cervical cancer, human papillomavirus, oncoprotein E6, oncoprotein E7, Papanicolaou 


\section{INTRODUCCIÓN}

El cáncer cérvicouterino $(\mathrm{CaCu})$ es el segundo cáncer en frecuencia en mujeres de todo el mundo. La mayoría de los casos ocurren en países en vías de desarrollo (1-3). La infección por el virus del papiloma humano (HPV) ha sido reconocido como un factor etiológico para el desarrollo del $\mathrm{CaCu}$ (4-6). Se han descrito más de 120 tipos de HPV y aproximadamente una tercera parte de ellos son capaces de infectar el epitelio del tracto genital $(7,8)$. Otros tumores relacionados con el HPV son del canal anal, vagina, vulva, pene y oral, de tal manera que se ha estimado que el HPV es responsable del $5,2 \%$ de todos los cánceres en el mundo $(9,10)$.

Los HPV tienen tropismo por las células epiteliales. Así, pueden producir infecciones tanto de piel como de mucosas. Los virus que son capaces de infectar las mucosas se dividen en genotipos de alto y bajo riesgo, de acuerdo a si su infección puede conducir o no al desarrollo de cáncer. Los HPV 6 y 11 producen verrugas benignas en el tracto genital, y no son oncogénicos. La infección está caracterizada por lesiones verrugosas y el tratamiento para su eliminación es costoso. Por otro lado, los HPV de alto riesgo (HR-HPV), causan lesiones mucho menos evidentes y son clasificados como potencialmente oncogénicos, ya que están asociados con más del $99 \%$ de los cánceres del cérvix. El número de HR-HPVs varían entre 13 y 19, pero los tipos HPV 16, 18, 31, 33, 35, 45, 51, 52, 56 y 58 conllevan constantemente un alto riesgo $(3,6)$. De estos, el HPV16 se encuentra en aproximadamente el $60 \%$ de todos los $\mathrm{CaCu}$, mientras el HPV18 está involucrado en un 10-20\%, mientras los HPVs tipo $31,33,35,39,45,51,52,56,58,59,68$ y 73 juntos constituyen el $20-30 \%$ restante de los $\mathrm{CaCu}$ [3]. El HPV ha sido implicado en el $85 \%$ del cáncer del canal anal, $50 \%$ del cáncer de vulva, vagina y pene, $20 \%$ del cáncer orofaríngeo y $10 \%$ del cáncer laríngeo y esofágico $(11,12)$. A pesar de que la tasa de progresión carcinogénica es relativamente baja, las infecciones con HR-HPV se encuentran en la mayoría de los cánceres cérvicouterinos humanos $(5,6)$.

Se requieren criterios claros para clasificar a los HPV en grupos de alto o bajo riesgo, basados en estudios epidemiológicos y moleculares, que provean el riesgo estimado sobre la evidencia funcional del potencial oncogénico de los diferentes tipos de HPV.

Los HPV son altamente transmisibles y la mayoría de los hombres y mujeres sexualmente activos adquirirán la infección durante su vida. Las infecciones genitales por el HPV son transmitidas principalmente por contacto sexual, pero no exclusivamente durante el coito. Mientras la mayoría de las infecciones son transitorias y benignas, la infección genital persistente con ciertos genotipos virales pueden conducir al desarrollo de lesiones precancerosas y de cáncer en la región anogenital.

Muchos virus que originan infecciones persistentes debido a su capacidad de modular o evadir la respuesta inmune, son caracterizados por una replicación viral continua a bajos o altos niveles (por ejemplo, el virus de la inmunodeficiencia humana y el virus de la hepatitis B) o por periodos de reactivación de una infección latente seguida por intervalos libres de la enfermedad (por ejemplo, el virus del herpes simple). Esto puede conducir a una variedad de problemas crónicos incluyendo neoplasias, inmunosupresión, enfermedades autoinmunes y falla orgánica selectiva $(1,13)$.

Las mujeres son infectadas por alguno de estos virus poco tiempo después del inicio de la vida sexual activa, y la mayoría de las infecciones ocurren en mujeres menores de 25 años $(14,15)$. Después de esa edad, la prevalencia disminuye rápidamente. En mujeres de edad media, las infecciones por HPV son transitorias, volviendo a observarse un incremento en las infecciones en mujeres de 30 años (16).

El CaCu está caracterizado por una fase premaligna bien definida, la cual puede ser detectada por examen citológico de células cervicales exfoliadas (prueba de Papanicolaou). Desde la implementación de la citología (Pap), la tasa del $\mathrm{CaCu}$ ha disminuido considerablemente (17), y a pesar de que la mayoría de las mujeres que han fallecido por CaCu nunca se realizaron una prueba de Pap, muchas de ellas recibieron resultados negativos de su prueba. Esto se debe a que la sensibilidad de la citología es limitada por el error del muestreo, donde pocas células son colocadas en el frotis, agregándose el error de interpretación, donde pocas células anormales no son identificadas entre la multitud de células normales que también se encuentran en el frotis cervical bien tomado. El error de muestreo más común es la falta de células de la zona de transición cervical (18). Otro problema asociado al Pap, se reporta como resultado ASCUS (de sus siglas en inglés atypical squamous cells of undetermined significance = células atípicas escamosas de significado incierto), el cual es un hallazgo citológico sugestivo, pero no concluyente de lesiones escamosas intraepiteliales. Esto genera incertidumbre en el médico hacia la conducta a seguir. ASCUS permanece como una entidad que se reporta en $5-10 \%$ de las pruebas de Pap (17).

Los cambios premalignos cervicales represen- 
tan un espectro de anormalidades histológicas que van desde un NIC 1 (displasia leve), NIC 2 (displasia moderada) y NIC 3 (displasia severa/carcinoma in situ) hasta cáncer invasivo (2). Aunque el tratamiento de los cambios cervicales premalignos es eficaz, también es un procedimiento ineficiente. Esto se debe a las incertidumbres que rodean a la historia natural de la neoplasia intraepitelial cervical (NIC). Las pruebas citológicas e histológicas, no pueden distinguir a las pocas mujeres con frotis anormales, que progresarán hacia un cáncer invasivo de la vasta mayoría que presentan anormalidades que presentarán regresión espontánea (1).

En los últimos años, con la intensa investigación que se ha realizado sobre la patogénesis del $\mathrm{CaCu}$, se ha logrado un gran progreso en la comprensión de esta enfermedad. La infección genital con HRHPV es muy común, y la mayoría de los individuos se curan de la infección con el tiempo, pero aproximadamente el $15 \%$ de las pacientes, no pueden eliminar el virus. La infección persistente con un virus HR-HPV es el principal factor de riesgo para desarrollar cáncer del tracto genital inferior $(7,19,20)$. Debido a la infección persistente del cérvix con genotipos carcinogénicos del HPV, se introdujo la prueba de detección del ADN del HPV para el tamizaje de $\mathrm{CaCu}$ (20). Después de 8 años de seguimiento, utilizando los dos tipos de test en la India, observaron que el diagnóstico por ADN reducía en un $53 \%$ el número de casos con cáncer cervical avanzado y en un $47 \%$ el número de muertes. Sin embargo, el método Pap sólo redujo en un $25 \%$ el número de casos con cáncer avanzado y sólo un $11 \%$ el número de muertes (21-23).

\section{CARACTERÍSTICAS GENERALES DEL VIRUS DEL PAPILOMA HUMANO}

Los HPVs son virus pequeños ADN de doble cadena, de la familia Papovaviridae. Aunque el genoma viral puede variar ligeramente entre los diferentes tipos de HPV, se acepta que típicamente contienen cerca de 8.000 pb y codifica en ocho o nueve marcos abiertos de lectura, los cuales son transcritos como ARNm policistrónicos $(24,25)$ (Figura 1). La cápside del virus está formada por dos proteínas. La proteína L1 es el elemento estructural primario, encontrándose 360 copias de la proteína organizada en 72 capsómeros en los viriones infectantes (26). La proteína L2 es un componente menor del virón y se cree que puede estar presente en el centro de los capsómeros pentavalentes en los vértices del virión (27). Esta proteína L2 interviene en la entrada del virus a las células, en la localización de los componentes virales en el núcleo, en la unión al $\mathrm{ADN}$, en la formación de la cápside y en la estabilidad (13). Ambas proteínas juegan un papel muy importante en mediar la eficiencia de la infectividad del virus $(25,27)$. La infección por HPV requiere que las partículas virales accedan a la capa basal epitelial y penetren a las células basales en división. Es bien conocido que previo a que los HPVs establezcan una infección, tienen que experimentar un complicado proceso para unirse y entrar a la célula huésped (28). Hay controversia sobre la naturaleza del receptor viral, pero se cree que son los proteoglicanos heparán sulfato (HSPGs) los receptores iniciales. Se ha observado que L2 de todos los virus HPVs secuenciados, contienen en su extremo amino terminal una secuencia consenso que es escindido por furina, una pro-proteína convertasa, y la escición por furina (29) se supone es necesaria para la unión y entrada del virus a la célula, ya que esto provoca un cambio conformacional de la cápside viral, seguido de la liberación de los HSPGs para la posterior asociación con un receptor putativo secundario, que se cree es una integrina 6 $(4,27,28,30,31)$. Otros estudios evidencian que el rompimiento de furina puede llevarse acabo en la superficie celular o dentro de un compartimiento endosomal temprano (30), y las cápsides se liberan en un compartimiento endosomal tardío, llevando a liberar el genoma asociado del endosoma hacia el citoplasma por un mecanismo que involucra el extremo C-terminal de L2 (32).

\section{CICLO DE VIDA DEL VIRUS DEL PAPILOMA HU- MANO}

El ciclo de vida del HPV está ligado al programa de diferenciación de la célula huésped infectada, el queratinocito, pero la expresión de altos niveles de proteínas virales y el ensamblaje viral ocurren exclusivamente en las capas superiores, es decir, en el estrato espinoso y en el epitelio granuloso del epitelio escamoso (33). Las células en la capa basal consisten en células troncales y células en tránsito que se están dividiendo continuamente y proveen un reservorio de células para las regiones suprabasales (34). La infección de estas células por el HPV conduce a la activación de la expresión en cascada de los genes virales que provoca la producción de aproximadamente 20 a 100 copias extracromosómicas del ADN viral por célula. Este promedio de número de copias es establemente mantenido en las células basales indiferenciadas a través del curso de la infección $(4,34)$. La integración viral es más común que ocurra en las células que contienen este número de episomas. En los episomas, la expresión de genes virales es mínima y en parti- 


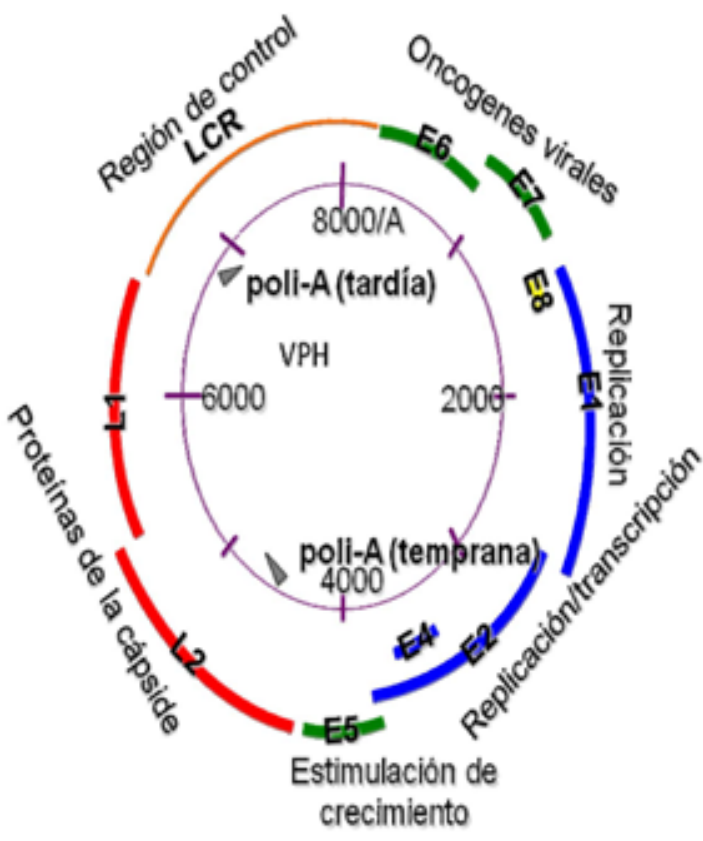

Figura 1. Virus del papiloma humano. $\mathrm{LCR}=$ regulación de la expresión génica y replicación viral. E6 y E7 considerados oncogenes ya que sus proteínas se unen a p53 y pRb, respectivamente. E1 y E2 son genes de expresión temprana necesarios para la replicación y transcripción del genoma viral. E4 es necesario para el ensamblaje y liberación viral. L1 y L2 codifican para las proteínas de la cápside.

cular, la expresión de los oncogenes E6 y E7 está bajo un control muy estricto, y sus proteínas son discretamente detectables. Cuando el queratinocito infectado entra al compartimento de diferenciación, sale del ciclo celular, hay una regulación positiva de la expresión de los genes virales, ocurre la replicación del ADN viral y entonces el número de copias virales aumenta al menos a 1000 copias/célula, y se observa abundante expresión de los genes tempranos E6 y E7 y de los genes tardíos (Figura 1) (35). Las infecciones genitales por el HPV son transmitidas principalmente por contacto sexual, se considera que a través de microabrasiones del epitelio que expone a la infección viral a las células de la capa basal $(4,36)$.

\section{INTEGRACIÓN DEL VIRUS DEL PAPILOMA HU- MANO}

Los HPVs pueden encontrarse en el material cervical en forma de episomas, en formas integradas o en forma mixta que contiene ambas. La in- tegración usualmente causa deleción o alteración del gen viral regulador E2, mientras retiene un segmento variable que incluye a los oncogenes E6 y E7 y la región reguladora corriente arriba. La sobreexpresión de E2 por los promotores heterólogos en las células huésped con el HR-HPV integrado, puede reprimir al promotor temprano del virus provocando una disminución drástica en la expresión de los genes E6 y E7. Así, la integración del HR- HPV y la deleción o alteración de E2 conduce al aumento de expresión de los oncogenes virales (37). Las células que tienen integrado al HR-HPV adquieren una ventaja de crecimiento sobre las células que albergan episomas del HR-HPV (el estado natural del virus en infecciones productivas) y muestran un aumento de inestabilidad genómica $(38,39)$.

La integración viral al genoma de la célula huésped ocurre corriente abajo de la expresión de los genes tempranos E6 y E7, frecuentemente en la región E1 o E2; esta interrupción provoca la pérdida del control negativo de la expresión del oncogén por la expresión de la proteína del gen regulador viral E2. Los transcritos derivados del virus integrado son más estables que los derivados del ADN viral episomal, y la integración del HPV 16 ha sido asociado con una ventaja de crecimiento selectiva en las células afectadas (38-40).

La prevalencia en células exfoliadas de cérvix o de tejido cervical de episomas o formas integradas del HPV o ambas, varía según el grado de severidad de la enfermedad, del tipo de HPV que se encuentre presente y del método utilizado para determinar el estado físico del virus $(31,32,41)$. Se ha propuesto que la identificación de formas integradas del HPV podría ser un biomarcador muy útil para la enfermedad progresiva. Sin embargo, hay varios problemas con esta propuesta. Primero, la identificación del pequeño número de formas integradas sobre una base de formas episomales es un reto técnico cuando sólo están disponibles células exfoliadas para el análisis. Segundo, si los genomas integrados están transcripcionalmente silentes, o si se obtienen poco tiempo después de la integración, entonces su detección puede tener una utilidad pronóstica limitada (4). Aunque las formas integradas se detectan en más del $40 \%$ de las mujeres con NIC 3 , la transcripción activa de las formas integradas se han reportado solamente en el $15 \%$ de las pacientes $(4,40)$. La detección de transcritos derivados de virus integrados nos proporcionaría información pronóstica más útil. Sin embargo, se ha demostrado que en los queratinocitos cervicales a los cuales se integrará el virus, solamente puede haber transcritos después de que ocurra una disminución del número de episomas que expresen 
E2 (34). Esta pérdida del gen E2 en los episomas se asocia con la activación endógena de los genes antivirales aumentando la expresión de los oncogenes virales en las células que poseen las formas integradas $(34,42)$.

Una vez que el virus logra penetrar a la célula huésped inicia la expresión de sus genes. Los productos de los genes pueden ser divididos en tempranos (E) y tardíos (L), dependiendo del momento en que se expresan durante el ciclo de vida viral. Las moléculas críticas en la replicación viral son E6 y E7, las cuales inactivan funcionalmente los productos de dos genes supresores de tumores muy importantes, el gen p53 y Rb, respectivamente. Ambos oncogenes inducen la proliferación, inmortalización y transformación maligna de las células infectadas.

\section{DE LA INFECCIÓN AL CÁNCER}

Los virus infectan los queratinocitos basales primitivos, pero los niveles de expresión elevada de proteínas virales y el ensamblaje viral, ocurren exclusivamente en las capas del estrato espinoso y granuloso del epitelio escamoso (Figura 2) (33). La expresión de genes virales está confinada al queratinocito, y no hay evidencia de que tales genes se expresen en otra célula que no sea queratinocito. Poco después de la infección, la replicación de los episomas virales parece ser independiente del ciclo celular y se producen aproximadamente de 50 a 100 copias por célula (8). Se cree que la célula deja este estado primitivo para transformarse en una célula proliferativa del epitelio. En esta etapa la expresión viral es mínima, la expresión de los oncogenes virales E6 y E7 están bajo un control muy estricto, por lo que sus transcritos son escasa- mente detectables. Cuando el queratinocito entra al estatus de diferenciación, sale del ciclo celular e inicia un aumento masivo en la expresión de los genes virales, formándose al menos 1000 copias de virus por célula, con abundante expresión de los genes tempranos E6 y E7 y la expresión de genes tardíos (35).

EI HPV codifica sólo una proteína para la replicación del ADN, la enzima E1 y además de esta la proteína viral E2, fuera de ello, la replicación viral es totalmente dependiente de la maquinaria de síntesis del ADN celular. El problema para los virus es que las ADN polimerasas celulares y los factores de replicación sólo se producen en células con mitosis activa. Para resolver este problema, los virus codifican proteínas del ciclo de vida viral, que reactivan la síntesis de ADN celular en células sin ciclo celular, inhibe la apoptosis y retarda el programa de diferenciación del queratinocito infectado, creando un ambiente que es permisivo para la replicación del ADN viral (43). Los detalles a fondo no son bien conocidos, pero los genes virales centrales para estas funciones son el E6 y el E7 (8).

En esta estrategia de replicación el ADN viral se replica y el virus se ensambla en una célula que estaba destinada a morir por causas naturales; no hay citólisis inducida por el virus, no hay necrosis y de ahí que no induzca inflamación, lo cual dificulta la activación de las células dendríticas y del inicio de una respuesta inmune efectiva. Este virus no produce viremia, por lo que pasa desapercibido por el sistema inmune. Además, al igual que todos los $A D N$ virus, tiene mecanismos para inhibir la síntesis de interferón por la célula huésped. Estas estrategias virales generan infecciones crónicas por largos periodos de tiempo sin que el huésped se entere.

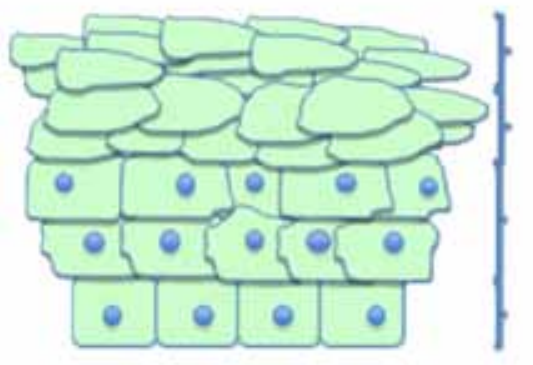

Epitclio sano
Estrato córnco

Estrato granuloso

Estrato espinoso

Estrato basal

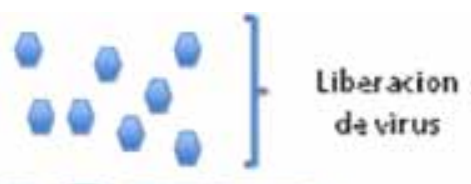

Figura 2. Se muestran las diferencias en las capas del epitelio cervical cuando está sano y cuando está infectado por el virus del papiloma humano. 
Durante la fase inicial de infección, el HPV existe como un episoma nuclear, pero la integración del HR-HPV al ADN del genoma huésped es un paso importante en la progresión neoplásica del cérvix (44). La integración causa deleción o alteración del gen regulador viral E2, en tanto retiene un segmento variable que incluye a los genes E6 y E7, lo cual origina el incremento de la expresión de los oncogenes virales $(37,38)$. Las células que contienen al virus integrado, adquieren ventajas de crecimiento sobre las que contienen episomas virales, lo cual provoca la expansión clonal de estas células. Estas células tienen inestabilidad genómica lo que conduce a la progresión de la malignización $(37,45)$.

\section{REFERENCIAS}

1. Woodman C, Collins, SI, Young LS. The natural history of cervical HPV infection: unresolved issues. Nat Rev Cancer 2007;7:11-20.

2. Parkin DM, Bray F. Chapter 2: The burden of HPVrelated cancers. Vaccine 2006;24:S3/11-25.

3. Munoz N, Bosch FX, de Sanjose S, Herrero R, Castellsague X, Shah KV, et al. Epidemiologic classification of human papillomavirus types associated with cervical cancer. N Engl J Med 2003;348:518-27.

4. Bosch F, Lorincz A, Muñoz N, Meijer CJ, Shah KV. The causal relation between human papillomavirus and cervical cancer. J Clin Pathol 2002;55:244-65.

5. zur Hausen $\mathrm{H}$. Papillomaviruses and cancer: from basic studies to clinical application. Nat Rev Cancer 2002;2:342-50.

6. Walboomers J, Jacobs MV, Manos MM, Bosch FX, Kummer JA, Shah KV, et al. Human papillomavirus is a necessary cause of invasive cervical cancer worldwide. J Pathol 1999;189:12-9.

7. Stanley M, Pett MR, Coleman N. HPV: from infection to cancer. Biochem Soc Trans 2007;35:1456-60.

8. Moody C, Laimins LA. Human papillomavirus oncoproteins: pathways to transformation. Nat Rev Cancer 2010;10:550-60.

9. Parkin DM. The global health burden of infectionassociated cancers in the year 2002. Int $\mathrm{J}$ Cancer 2006;118:3030-44.

10. de Sanjosé S, Diaz M, Castellsagué X, Clifford G, Bruni L, Muñoz N, et al. Worldwide prevalence and genotype distribution of cervical human papillomavirus DNA in women with normal cytology: a meta-analysis. Lancet Infect Dis 2007;7:453-9.

11. Pereira R, Hitzeroth II. Insights into the role and function of L2, the minor capsid protein of papillomaviruses. Arch Virol 2009;154:187-97.

12. Garland SM, Smith JS. Human Papillomavirus Vaccines. Current status and future prospects. Drugs 2010;70:1079-98.

13. Martinic M, von Herrath, MG. Novel strategies to eliminate persistent viral infections. Trends Immunol 2008;29:116-24.

14. Smith J, Melendy A, Rana RK, Pimenta JM. Agespecific prevalence of infection with human papillo- mavirus in females: a global review. J Adolesc Health 2008;43:S5-25.

15. Estadísticas a propósito del día mundial contra el cáncer. Datos Nacionales 2008. In, INEGI.

16. Bosch FX, de Sanjose S. The epidemiology of human papillomavirus infection and cervical cancer. Dis Markers 2007;23:213-27.

17. Nanda K, McCrory DC, Myers ER, Bastian LA, Hasselblad V, Hickey JD, Matchar DB. Accuracy of the Papanicolaou test in screening for and follow-up of cervical cytologic abnormalities: a systematic review. Ann Intern Med 2000;132:810-9.

18. Boulet G, Horvath CA, Berghmans S, Bogers J. Human papillomavirus in cervical cancer screening: important role as biomarker. Cancer Epidemiol Biomarkers Prev 2008;17:810-7.

19. Liaw K, Hildesheim A, Burk RD, Gravitt P, Wacholder $\mathrm{S}$, et al. A prospective study of human papillomavirus (HPV) type 16 DNA detection by polymerase chain reaction and its association with acquisition and persistence of other HPV types. J Infect Dis 2001;183:8-15.

20. Mayrand M, Duarte-Franco E, Rodrigues I, Walter SD, HanleyJ, Ferenczy A, et al. Human papillomavirus DNA versus Papanicolaou screening tests for cervical cancer. N Engl J Med 2007;357:1579-88.

21. Castle P, Fetterman B, Thomas Cox J, Shaber R, Poitras N, Lorey T, Kinney W. The Age-Specific Relationships of Abnormal Cytology and Human Papillomavirus DNA Results to the Risk of Cervical Precancer and Cancer. Obstet Gynecol 2010;116:76-84.

22. Idelevich $P$, Kristt D, Schechter E, Lew S, Elkeles A, Terkieltaub $\mathrm{D}$, et al. Screening for cervical neoplasia: A community-based trial comparing Pap staining, human papilloma virus testing, and the new bi-functional celldetect $\circledast$ stain. Diagn Cytopathol 2011;doi:10.1002/ dc.21729.

23. Weinberg C. HPV screening for cervical cancer in rural India. N Engl J Med 2009;360:1385-94.

24. Hebner C, Laimins A. Human papillomaviruses: basis mechanisms of pathogenesis and oncogenicity. Rev Med Virol 2006;16:83-97.

25. Doorbar J. Molecular biology of human papillomavirus infection and cervical cancer. Clin Sci (Lond) 2006;110:525-41.

26. Hagensee M, Yaegashi N, Galloway DA. Self-assembly of human papillomavirus type 1 capsids by expression of the L1 protein alone or by coexpression of the L1 and L2 capsid proteins. J Virol 1993;67:315-22.

27. Modis Y, Trus BL, Harrison SC. Atomic model of the papillomavirus capsid. Embo J 2002;21:4754-62.

28. Richards R, Lowy DR, Schiller JT, Day PM. Cleavage of the papillomavirus minor capsid protein, L2, at a furin consensus site is necessary for infection. Proc Natl Acad Sci U S A 2006;103:1522-7.

29. Day P, Lowy DR, Schiller, JT. Heparan SulfateIndependent Cell Binding and Infection with Furin-Precleaved Papillomavirus Capsids. J Virol 2008;82:12565-8.

30. Li W, Wang W, Si M, Han L, Gao Q, Luo A, et al. The physical state of HPV16 infection and its clinical significance in cancer precursor lesion and cervical carcinoma. J Cancer Res Clin Oncol 2008;134:1355-61. 
31. Doorbar J. The papillomavirus life cycle. J Clin Virol 2005;32:S7-15.

32. Klaes R, Woerner, SM, Ridder, R, Wentzensen, N, Duerst, M, Schneider, A, et al. Detection of highrisk cervical intraepithelial neoplasia and cervical cancer by amplification of transcripts derived from integrated papillomavirus oncogenes. Cancer Res 1999;59:6132-6.

33. Pett M, Herdman, MT, Palmer, RD, Yeo, GS, Shivji, MK, Stanley, MA, et al. Selection of cervical keratinocytes containing integrated HPV16 associates with episome loss and an endogenous antiviral response. Proc Natl Acad Sci U S A 2006;103:3822-7.

34. Middleton K, Peh W, Southern S, Griffin H, Sotlar K, Nakahara $\mathrm{T}$, et al. Organization of human papillomavirus productive cycle during neoplastic progression provides a basis for selection of diagnostic markers. J Virol 2003;77:10186-201.

35. Longworth M, Laimins LA. Pathogenesis of Human Papillomaviruses in Differentiating Epithelia. Microbiol Mol Biol Rev 2004;68:362-72.

36. Alazawi W, Pett M, Arch B, Scott L, Freeman T, Stanley MA, Coleman N. Changes in cervical keratinocyte gene expression associated with integration of human papillomavirus 16. Cancer Res 2002;62:6959-65.

37. Jeon S, Allen-Hoffman BL, Lambert PF. Integration of Human Papillomavirus Type 16 into the Human Genome Correlates with a Selective Growth Advantage of Cells. J Virol 1995;69:2989-97.

38. Jeon S, Lambert PF. Integration of human papillomavirus type 16 DNA into the human genome leads to increased stability of E6 and E7 mRNAs: Implications for cervical carcinogenesis. Proc Natl Acad Sci USA
1995;92:1654-8.

39. Andersson S, Safari H, Mints M, Lewensohn-Fuchs I, Gyllensten U, Johansson B. Type distribution, viral load and integration status of high-risk human papillomaviruses in pre-stages of cervical cancer (CIN). $\mathrm{Br} \mathrm{J}$ Cancer 2005;92:2195-200.

40. Herdman M, Pett MR, Roberts I, Alazawi WO, Teschendorff $A E$, Zhang $X Y$, et al. Interferon-beta treatment of cervical keratinocytes naturally infected with human papillomavirus 16 episomes promotes rapid reduction in episome numbers and emergence of latent integrants. Carcinogenesis 2006;27:2341-53.

41. Evander M, Frazer IH, Payne E, Qi YM, Hengst K, McMillan NA. Identification of the alpha6 integrin as a candidate receptor for papillomaviruses. J Virol 1997;71:2449-56.

42. Bechtold V, Beard P, Raj K. Human papillomavirus type $16 \mathrm{E} 2$ protein has no effect on transcription from episomal viral DNA. J Virol 2003;77:2021-8.

43. Wentzensen N, Vinokurova S, von Knebel Doeberitz $M$. Systematic review of genomic integration sites of human papillomavirus genomes in epithelial dysplasia and invasive cancer of the female lower genital tract. Cancer Res 2004;64:3878-84.

44. Pett M, Alazawi WO, Roberts I, Dowen S, Smith DI, Stanley MA, et al. Acquisition of high-level chromosomal instability is associated with integration of human papillomavirus type 16 in cervical keratinocytes. Cancer Res 2004;64:1359-68.

45. Duensing $S$, Münger K. The Human Papillomavirus Type 16 E6 and E7 Oncoproteins Independently Induce Numerical and Structural Chromosome Instability. Cancer Res 2002;62:7075-82. 